Published in: JOURNAL OF PHILOSOPHY OF EDUCATION 46(4):574-588 Nov 2012

DOI: $10.1111 /$ j.1467-9752.2012.00888.x

\title{
The future of teacher education
}

\author{
Alis Oancea and Janet Orchard
}

\section{Abstract}

Conceptions of teaching quality and teacher accountability, and the values and assumptions which underpin them, are relatively under-examined by policy makers. We suggest ways in which philosophers might address this deficit, with reference to policy concerns found in the United Kingdom (UK). Further philosophical questions are generated by this process of reflection and we offer a partial analysis of those we judge to be of particular significance. While optimistic generally, we identify three challenges to asserting a role for philosophical analysis in policy, practice and research concerned with teacher education, and urge philosophers of education to engage in constructive dialogue with other critical and reflective thinkers in the field of education.

\section{The future of teacher education}

\section{Introduction}

The values and assumptions that underpin particular conceptions of teaching quality and teacher accountability in particular remain, relatively speaking, under-examined. In this paper we illustrate how philosophers might contribute to addressing this deficit, a question that is partly empirical, and partly philosophical. We start by reviewing the recent policy contexts for teacher education in the United Kingdom (UK), which illustrate the ways in which opportunities for communication between philosophers of education and teacher education policy-makers are shaped by time and space. Griffiths, calls these opportunities 'promising contexts for engagement' (2012, p. 7). We dwell on Whitty et al.'s suggestion (2012) that the four distinct policy contexts of which the UK is constituted work as examples of policy turbulence at regional and international levels.

We then draw upon examples from an initiative called 'Philosophical Perspectives on the future of Teacher Education (PPfTE) ${ }^{i}$ to suggest several possible ways in which philosophical reflection on teacher education may be relevant to, engaging for, and influential among policy, research and practitioner communities in teacher education. These suggestions are framed by several wider philosophical questions. What do we 
mean by philosophy of education? What do we mean by policy relevance, engagement and influence? What makes them worthwhile? Further questions have a more marked empirical component. Can shared understandings of philosophy of education be developed and communicated across the different professional communities involved? What is policy? Does it make sense to talk of policy engagement on the part of, and the influence of, philosophy, rather than that of philosophers, of education (see Bridges, 2003b; Saunders, 2007, Griffiths, 2012)? How do we know that policy relevance and influence have been achieved?

We attempt a partial analysis of these central questions, relating them to the particular context of teacher education policy in the UK, as their fuller exploration is outside the scope of this paper. In bringing them together in the final section of the paper, we also identify three particular challenges faced in any attempt to assert a role for philosophical analysis in policy, practice and research concerned with teacher education. In general we are optimistic about the potential to influence policy formation in this area, tempered by a recognition of the limitations imposed by clear structural disadvantages faced by philosophers of education, including lack of funding. We conclude that this intensifies the need for philosophers to engage constructively in dialogue with other critical and reflective resources in education.

\section{Contexts for engagement and influence: teacher education policies in the UK}

\section{Divergent interpretations of teaching and teacher education}

State systems of mass education are shaped through societal consensus over what aims and objectives should be pursued and what counts as an educated young person, and therefore by what counts as an effective investment of public funds. This support through the public purse, via tax contributions, embeds a (reasonable) general expectation that the use of those resources will be accounted for. Standards and measures of performance, systems through which that performance may be monitored and reported, as well as quality assurance structures and mechanisms intended to regulate this process of accountability, have flourished in recent times within neo-managerialist approaches to public policy and administration developed in Western countries. One way in which these phenomena may be viewed is as markers of the point at which policy and professional interpretations of the nature of teaching and teacher education practice may diverge, raising questions about the most adequate ways in which one might assess and critique their quality.

For example, administrative and policy documents may refer to accountability in a technical sense, using the language of audit, monitoring, and formal responsibility, while researchers and teacher educators may draw on an ethical and relational concept of accountability, emphasizing the place of trust, integrity and professional responsibility (see Winch, 2010, 2001; O'Neill, 2002) in their practice. These distinct notions of accountability go on to inform different, potentially conflicting discourses of control and regulation to determine notions of quality, standards and performance, as well as issues of professionalism across education in general, and in teacher education specifically. 
These discourses diverge in their understanding of teaching practice, and thus of the kinds of teacher education that might enable it to come about.

In a strictly managerial sense, teaching might be described in terms of being an operative function, even though such an account may be anathema to some. Teaching in managerialist terms is one part of an institutional mission and its associated implementation plans, subject to (mostly output-based) pre-defined measures of success. Its technical (for example, issues of procedure, clarity, transparency, and application of rules) and instrumental (for example, targets, performance indicators, and milestones) aspects take priority. The foregrounding of technique makes practice amenable to control, not just internally, by its own goods, but mainly externally, via formal channels for regulation and sanction. In other words, it becomes manageable, contained: contrasting sharply with alterative possible understandings of teaching, for example as a situated educative action in a social space, in organic pairing with learning, and laden with moral complexity (e.g. Ellis et al. 2010).

Moreover, the policy documents that have framed recent public debates around the nature and purposes of teaching practice, while still constructed around the themes of quality and accountability in teacher education, have been decidedly different in nature within the four separate jurisdictions that comprise the UK. We will return to examples drawn from these contexts, which we take as illustrative of wider trends and debates at the international level, throughout the paper.

In England, the 2010 White Paper on The Importance of Teaching (DfE, 2010), together with the Implementation Plan published in November 2011 (DfE, 2011a) and the new standards for teachers' conduct and performance (DfE, 2011b), used a language of autonomy, empowerment and professionalism to argue for more school-based initial teacher education (ITE). The reforms announced in these documents included increased selectivity in ITE recruitment, which should actively involve schools and more classroom-based teacher training, both seen as means to improving quality in teaching and teacher education through a rebalancing of values (including moral values) and priorities. The intention behind the publication of new standards for teachers in England (DfE 2011b) was to 'enhance the quality and moral purpose of the teaching profession and make a significant improvement to teaching by encouraging teachers to focus on the qualities and attributes that matter most' (Gove, 2011). No necessary relationship is assumed between these and a university-based period of initial preparation for teaching, hence the relaxation in July 2012 of rules regarding the employment of unqualified teachers in certain kinds of state-funded schools in England (Harrison, 2012).

The House of Commons Education Committee report, Great Teachers: attracting, training and retaining the best, has endorsed many of these changes, including the new standards, while also recognizing the value of school-university partnerships and cautioning against a diminution of the role of universities in teacher training (House of Commons Education Committee, 2012). The reaction of school-based practitioners to these proposals has been mixed. Some have moved quickly to implement the new Schools Direct route into teaching (established by the 2010 White Paper), while others 
have chosen to pursue new opportunities to provide Continuing Professional Development (CPD) for teachers, yet remained in established and familiar initial teacher education partnerships, predominantly with higher education institutions (HEIs). Representatives of all these institutions have debated intensely the threats and opportunities created by these recent policy-led developments.

In Scotland, by contrast, the recommendations of the December 2010 Donaldson review, Teaching Scotland's Future, were met with wide-ranging support (see e.g. the Scottish Government's response, 2011), from across the educational community. These proposals express a desire to improve the quality of teaching and school leadership in Scotland through a process that includes recognition, rather than rebalancing, of professional values. They also aim to develop a model of less fragmented career-long teacher education, by 'striking the right balance and connections between university experience and school experience' (p. 12). Another key focus of the Donaldson review is a concern with promoting high standards in teaching through an emphasis on 'extended professionalism' (p. 5), which largely supports the direction of the current General Teaching Council for Scotland's standards for teaching (GTCS, 2006; see also Whitty et al. 2012).

In Northern Ireland, the government consultation document, Teacher Education in a Climate of Change (DELNI/DENI, 2010) identified a number of priorities for provision. As in England, the streamlining of the framework of teacher competences has proved one important consideration, while balancing more successfully the supply of and demand for new teachers is a particular local issue. Unlike in England, strengthening school - HEI partnerships in ITE provision has been identified as means by which to develop leadership within the teaching profession as well as to ensure a less fragmented early career experience for new teachers, including opportunities for Continuing Professional Development. Similarly in Wales, the General Teaching Council for Wales's advisory paper, Raising the Bar in ITET and Early Career Development (GTCW, 2011), as well as focusing on ensuring higher quality of entrants to ITE programmes, identifies oversupply of qualified teachers, and enhancing opportunities for engagement with research and scholarship during ITE, to be of particular concern (for a longer term review of ITE in Wales prior to 2011 see the Furlong Report: Furlong et al. 2006).

While there are significant differences across the four jurisdictions of the UK in this documentation, some common themes do emerge. These include supporting some level of knowledge exchange between HEIs and schools; recognizing the importance of individual and professional values in teaching; and acknowledging the need for teachers to be aware of the findings of educational research (in particular through teacher inquiry and reflective practice) throughout a teaching career. Still, in the English White Paper and associated documents, substantive mentions of research are scarce where, for example, research is mentioned only twice in the chapter on teacher training, and in each case in a text box describing the Finnish system. In contrast, the Donaldson report insists repeatedly upon the importance of research-informed professionalism in teaching. It argues for integrating research (skills and knowledge) and engagement with theory within policy-supported models of teacher and teacher educator professionalism and in teacher 
education partnership models and practices, including joint teacher education appointments.

These distinctive policy contexts afford different opportunities for the engagement of philosophy and philosophers with policy and policy-makers. Were such engagement to be achieved, it might be serendipitous or indirect, for example through collaborative work of philosophers of education with teacher educators and teacher education researchers (which is still to achieve full development and recognition - see Edwards et al. 2003; Menter et al. 2010). Alternatively it might occur through planned, strategically determined public engagement activity, potentially enabling subtle shifts in the terms of public debates and in public perceptions of the issues at stake and their implications. The media offer another potential channel through which philosophers might provoke policy responses. Philosophical training (such as initiation into distinctively philosophical modes of argument and questions) tailored to the needs of policy makers at various stages of their career might also be a way of bringing philosophy and policy together.

More direct influence is also possible, for example by taking advantage of opportunities for philosophers' participation in policy advisory committees and in parliamentary inquiries, or through their work with think-tanks and lobbying groups. The PPfTE initiative (see note 1) is an example of how contexts may also be deliberately created for the purpose of dialogue between policy-makers, practitioners and researchers from different traditions and for enabling the development and refinement of awareness of the environments of each other's work. Other contexts with similar purposes, also from UKbased education research, include the 2008-2010 Strategic Forum for Research in Education, a partnership across all sectors and countries of the UK that included learned society support, and the Applied Educational Research Scheme, a government-funded multi-institutional initiative in Scotland (2003-2008).

\section{The relevance of philosophy for policy formation}

There is a growing body of literature, in fields such as health, science and technology, and sociology, describing the varied ways in which research and scholarship, in general, can connect with different levels and stages of policy, from policy formation to evaluation (a literature summarized in, for example, Oancea, 2011b). 'Dissemination', 'knowledge transfer' and 'knowledge exchange' and 'mediation' have successively captured the imagination of authors working in this area. More recently, in the UK context, emphasis has been placed on the need to capture and demonstrate research 'impacts'. This might be retrospectively, for example, for the six-yearly national assessment of Research Excellence, which evaluates research conducted in higher education institutions in order to inform public funding decisions; and/or prospectively, for example, as part of grant applications to a range of public funding bodies.

This process has prompted even more empirical and theoretical work aiming to elucidate the nature, processes, drivers, and barriers to achieving influence. For example, Levitt et al. (2010) point out the non-linear, often contingent nature of the 'impacts' of philosophy 
on policy. Much of this work is based on sociological and policy analysis and has conceptual as well as practical aims, such as informing research funders' and higher education institutions' decisions about research strategy and governance.

For the purposes of this paper, we will focus on the stage of policy formation, seen as a process of identifying, defining and framing problems. We will consider a range of evidence, interests and purposes in order to form judgments about the nature and priority of these problems and about the grounds for different possible courses of action, as well as making, communicating and defending particular choices (or 'solutions'). Policy reasoning and justification are, of course, also part of other components of the policy process, including policy implementation and evaluation, as well as different agents' interpretation of, and responses to, policy.

Some of the problems that policy documents such as those described above purport to tackle are generic educational complexities that translate into particular concerns for policy makers. These might include, for example, the articulation between secondary and higher education, the indicators of teacher effectiveness, or the link between different models of teacher education and teacher effectiveness. These problems are the focus of empirical research, but, arguably, many of them are also amenable to philosophical treatment. For example, considerable tensions in policy making that could be addressed profitably by philosophical interrogation include those between institutional or professional autonomy and control, or those between craft-apprenticeship, deliverytraining, and applied scholarship-formation models of teaching and teacher education.

However, it is not clear that the reforms to teacher education currently being proposed in England are thoroughly thought through in this way, nor indeed how well informed they are by the findings of educational research in general (this may be less of a concern in Scotland). The responsibility for such lack of engagement lies not only with policy actors (among whom Griffiths, 2012, found little interest in, or knowledge of, philosophy of education), but also with the various communities of philosophers of education, some of whom may be reluctant to accept or to actively pursue engagement with the policy and political arenas (Saunders, 2012; Oancea and Bridges, 2009).

The policy problems described above require situated policy judgments that take into account, not always systematically, a wide range of interests, aims, sources and forms of evidence. The necessary (though possibly not sufficient) 'conditions for the rationality' of such policies may include exposure to criticism of the intelligibility, justification and coherence of their underlying normative principles. Under consideration too might be the substance, reliability, implications and relevance of the grounds on which they were designed (Bridges and Watts, 2009, drawing on White, 2007).

Philosophical treatment of such second-order questions can help both to illuminate and challenge 'the grasp of the concrete' (Peters, 1966, p. 15) inherent in policy formulation, while also 'bringing into focus what is important' (Laugier, 2011, p. 997, drawing on Cavell and Austin). The capacity to move beyond established ways of thinking, in order to reflect on alternative conceptions of institutional practices, roles and future states of 
being, shifts ideas of what is possible. Engrained interests are opened up for consideration, potentially displacing existing hierarchies and priorities. In so doing, a sense of what matters (in policy as well as in ordinary life) shifts, thus 'relocating importance' (Laugier, 2011, p.999; see also Cavell, 1979, Wittgenstein, 2001, §118).

There are further, even more characteristically philosophical, problems that beset current policy-making (in England, as illustrated in recent policy documents, but also beyond this context), such as questions about the nature of teacher professionalism, the role of theory in teacher preparation, or the conditions that enable rationally defensible practical judgment in teaching. While current policy-making emphasises school-based learning as a necessary part of preparation for the practice of classroom teaching, the assumption that it is sufficient is open to question. Concern about the theory-practice divide in a teacher's professional development presupposes that theory does indeed have a role to play, drawing on well-established arguments in the field (see Hirst and Carr 2005). Some philosophers might challenge the role that being well-versed in theory is helpful to teachers, while others have defended the idea strenuously (see e.g. Winch, 2012).

Other questions follow from this general theme. What knowledge, values, dispositions and skills $d o$ teachers need to educate others well? Do teachers need to be good people, and if so, in what sense? How can they have confidence in the quality of their pedagogical judgment and the soundness of their educational beliefs? How can teacher education and policy help foster and develop these abilities and the conditions in which they can be exercised? These and other characteristically philosophical concerns remain relatively unexamined in policy-centred debates about teacher education. The problems they raise are philosophical in nature, concerning the nature of the world and the self, the nature, sources, forms and dynamics of knowledge, or the principles and values of the conduct of life. There is considerable scope, as well as need, for further philosophical reflection on these matters.

\section{Philosophy and teacher education policy and practice: examples from the PPfTE initiative}

Within the limitations of this shared understanding, what can philosophers of education contribute to the shifting landscape of teacher education policy in the UK, Europe and beyond? The modes of enquiry and philosophical arguments showcased at the PPfTE events were intended for audiences that included representatives of the immediate communities of philosophers of education, but also teachers, policy-makers, teacher educators and researchers working in other traditions. Participants at PPfTE events shared a common concern to illustrate different ways in which a contribution from philosophy to teacher education policy, practice and research might be made. Examples generated included: clarifying the meanings of words, concepts, and propositions, their logical implications, and the normative assumptions underpinning their policy usage (Wringe, 2011, Pring, 2011); offering second-order reflection on the conditions for democratic conversations and practical deliberation in teaching and teacher education (Menter, 2011, Griffiths, 2011); pursuing 'intelligent argumentation' (Phillips, 2007), perhaps in an 
alternative language, for alternative solutions to substantive educational problems (Winch, 2012); and exposing presumptions of thought to critical scrutiny (Higgins, 2011; Standish 2012, Heilbronn, 2012). We describe some of these contributions below.

\section{Clarifying and challenging presumptions}

Some contributions to the PPfTE initiative have been concerned to clarify the meanings of words, concepts and propositions and their logical implications. For example, Pring (2011) clarifies the conceptual differences between notions of 'instruction', 'training' and 'teaching', to seek a notion of teaching that transcends current neo-managerial language. Foreman-Peck (2012) challenges the assumption that it is sufficient for early career professional development programmes for teachers to focus solely on the immediate conditions of learning and teaching in the classroom, and argues that it is necessary to nurture teachers so that they have the resources to sustain a career in the longer term.

Critically appraising policy and practice in a constructive way within the analytical tradition of philosophy of education, Wringe (2011) questions the representation of teaching as a craft in current policy discourse in the UK. There may be certain routine procedures, as well as role-specific skills, which teachers need and for which a workplace-based training led by practitioners might be most suitable. However, Wringe insists that teachers must also be educated, defining education as a reflective and intellectual process though which teachers develop certain attitudes of mind. Teachers, on Wringe's account, should be able to appreciate that notions of education are contested, with some arguably of greater worth than others.

The characteristic preoccupation of philosophers with exposing presumptions of thought to critical scrutiny is of particular relevance to teacher education policy. For example, how justified, a philosopher might ask, is the belief, made explicit in many recent policy and inspection documents in the UK, that teaching is some kind of 'mission' or 'calling'? Taking the theme of Higgins' (2011) recent special edition of the Journal of Philosophy of Education, also discussed in Higgins' contributions to two of the PPfTE events, are there not considerable difficulties with the notion of the 'selfless' teacher, captured succinctly in Gronn's (2003) account of unhealthily 'greedy' attitudes towards professional work? Higgins redefines teaching as an ethical quest, in which the personal fulfilment of the teacher herself is bound up with a concern for the well-being of her students. Good teachers need to be good people, argues Higgins, on what he terms a 'selfulness' account of the good.

\section{Illuminating practice and 'intelligent argumentation'}

Philosophy can usefully be applied to thinking about teacher education to support practical deliberation at different levels and on a range of aspects of educational policy and practice. Such considerations might be concerned with the decisions that teachers and teacher educators might use to justify particular everyday decisions in classroom situations. It might help them to address general moral and ethical dimensions of teaching 
practice, for example questions like: why teach these students, this content, in this context, and in this way? What course of action should I take in this situation? Other, more specific concerns that might exercise teachers include: are my students free to choose what they want? Should I/ do I/ can I encourage that freedom, and if so, by what means?

Hence Griffiths (2011) opens up ontological concerns about the embodied nature of pedagogical relations in learning and teaching. Focussing on the Donaldson report (see above) she welcomes its recognition of teaching as a complex and collegial practice requiring professional judgement and reflection but criticizes its silence on the ongoing and complex matter of sustaining pedagogic relations, given their propensity to be both contingent and malleable. This phenomenon is also under-researched yet has clear and important implications for the development of teacher education. Meanwhile Aldridge (2011), also starting from an ontological concern with the nature of teachers' experience during learning, pursues the question of how far, if at all, transformational experiences of heightened intensity - that take place in particularly significant encounters during the professional formation of a teacher - be captured adequately in language.

A philosophical contribution to teacher education might stimulate reflection by introducing alternative language, asking questions, or identifying alternative solutions to substantive educational problems. For example, Winch $(2011,2012)$ seeks to define the knowledge, values, dispositions and skills that teachers need to educate others well and offers an account of the role of research-based knowledge and philosophical questioning in supporting the formation and refinement of good teachers' situational judgement. If this position is broadly accepted it creates further philosophical issues, not least in relation to the tension we highlighted earlier between the ethical and relational concept of accountability - predicated on trust, integrity and professional responsibility - that this notion of professional judgement espouses, and accountability in a technical sense, framed in the language of audit, monitoring, and formal responsibility (see above).

Our own interest in the development of a language that captures the subtleties of professional practice along Aristotelian lines has encouraged us to pursue the notion of a 'good teacher' who combines theoretical knowledge (episteme, theoretike), technical skill (techne), and practical wisdom (phronesis) (Oancea and Orchard, 2012). In agreement with Winch, we identify a clear place for theory in teacher education. At the same time, we recognize the worth of accounts of the practical wisdom of teachers developed along alternative lines, for example by Biesta $(2011,2012)$ and Hogan (2012), which promote a different conception of the theory-practice relationship.

A concern with the values that underpin particular accounts of 'good teaching' and 'good teachers' has also captured the imagination of teacher educator colleagues who have engaged with the philosophical work explored in the PPfTE. For example, Mutton (2011) has trialled a workshop activity at two PPfTE events, in which teacher educators and philosophers were invited to consider eight different and sometimes competing sets of professional 'standards' for teachers, taken from different educational contexts over time and place. 


\section{Reflection on the conditions for democratic policy and practice}

Philosophical argument may also nurture discussions about the role of democracy in education and teacher education, focusing on the balance of trust that may reasonably be afforded to teachers, as professionals responsible for holding their own behaviour to account; or the extent to which mechanisms of public governance of teaching and teacher education are needed. Hinchliffe (2012), for example, raises questions about the authority of the teacher in the new educational landscape emerging in a school system in England outside state control, while Menter 2011) identifies as a particular strength of teacher education in Scotland the fostering of a 'democratic intellect' (Williams, 1961) in teachers, and in public deliberation about education as a whole.

\section{The modesty of philosophy}

Consideration of the relationship between philosophy and policy suggests the adoption of an attitude of tempered optimism. By this we mean that while recognizing the opportunities and potential for policy relevance, engagement and influence enjoyed by our discipline, this must be tempered by an understanding of the challenges - as well as limitations - philosophy and philosophers face in attempting to influence policy formulation, implementation and evaluation.

A first challenge faced by such attempts is that of disciplinary distinctiveness. The ways in which we conceive of the relationships between philosophy, practice (policy included) and other modes of inquiry shape the nature of the claims that we can sensibly make about philosophy's actual and potential contribution to educational practice, policy and research. If policy problems require synergy, rather than neat division of labour, then what exactly is it that philosophy of education can contribute to complement other disciplines, in particular those closely linked with empirical or factual research?

In making the case for philosophical reflection on the future of teacher education, philosophers should be wary of making claims to pre-eminent or privileged contributions, when so many other theorists reflect critically and systematically on issues of this kind. Philosophers of education have long debated whether teacher education, and in particular the education of effective teachers, is a matter that may be best addressed through empirical research, rather than philosophical argument (see Winch and Gingell, 2004), while also becoming 'hesitant about saying that conceptual issues can be clearly distinguished from empirical ones' (Peters, 1973, p. 2). The discussion in this paper of the roles philosophy might play in teasing out and addressing second-order questions, and in exploring alternative approaches, tools and ways of analysis that can challenge or illuminate the treatment of first-order questions, suggest that there may be space for complementarity of some kind. 
Another major challenge to claiming a distinctive role for philosophical reflection on policy comes from the many different ways in which policy and its sources can be conceived. Different ways of conceiving of policy rationality have different implications for how we might construe some openings for philosophical contributions to these processes. In its early days, some versions of the evidence-based policy movement saw it as an orderly and transparent process, drawing linearly on research findings for its choice of means; the normative backdrop against which these choices are made stayed out of view. More refined versions of evidence-informed policy make research one among a series of contributing factors to policy decisions, while still holding onto a hierarchy of what ought to count as reliable sources of evidence (Oancea and Pring, 2009).

However, policy formation is also practical judgment in political, as well as cultural and educational, and thus normative, spaces. Policy formation in this sense allows for individual deliberation, albeit in the public sphere; it is more of a play of intentions and accretion of normative judgments, backed by situational understanding, than just regulated production of documented articulations of consensus about aims and means. A wide range of conceptual and empirical sources compete for space as sources of policy ideas (Griffiths, 2012; Nutley et al. , 2007). Philosophy may help create a pause in the transit from reasons and 'evidence' to policy, and provide a moment of silence charged with (epistemological) doubt and (normative) interrogation. Alongside other modes of education research, it can seek to 'expose, critique, interpret, reinterpret, construct and deconstruct the normative assumptions of policy' (Bridges and Watts, 2009, p. 50) in light of what may count as 'morally and educationally defensible principles' (Davis, 1999, p. 400).

Finally, there is the issue of the confidence (Conroy, Davis and Enslin, 2009; Griffiths and Macleod, in Bridges, Smeyers and Smith, 2009) that we can have in the potential efficacy of policy makers' engagement with philosophy; and in that of philosophers with policy-making. What philosophy can do for policy is, at one extreme, to contain the 'possibility of foolishness' and increase 'the likelihood of wisdom' (Fielding, 2000, p. 377). At another it is, more modestly, to help 'illuminate complexities' and 'encourage further discussion' (McLaughlin, 2000, p. 451). In a third, more specific formulation (see e.g. Conroy, David and Enslin, 2009), if philosophers are to help scrutinize the quality of policy judgments and the inductive reasoning from which they arise, and if they are also to help question and clarify the values shaping these judgments, then the quality and normative background of their own claims need to be open to scrutiny.

In other words, in their engagement with policy, any influence that they, and their discipline, may have on it, needs to be defensible philosophically, as well as functionally. This requirement hints at the lack of agreement about the worthwhileness of policy engagement (Griffiths, 2012), and related concerns about threats to academic rigour as well as integrity when the terms of engagement are set by the concerns of policy rather than philosophy. A possible response to these objections is to see policy engagement as a matter of moral responsibility for the quality of the judgments that underpin the actions we endorse (see Bridges and Watts, 2009, who draw on Clifford's 'ethics of belief', 
1879). Winch and Gingell (2004) go as far as arguing that 'without political and policy engagement', philosophy of education would be 'a diminished discipline' (p. 3).

\section{Conclusion}

In this paper we have suggested that while the challenges of distinctiveness, rationality and confidence are serious and complicated, they do not preclude contributions by philosophy and philosophers to policymaking. These contributions may take different shapes, from helping to create and sustain the conditions for sound policy judgment in teacher education, to public reflection on the conditions for wider democratic conversations about policy.

The relationship between philosophy of education and policy communities may be hindered by particular structural disadvantages that face philosophers of education seeking to influence the direction of public policy on teacher education in the UK, not least the scarcity of funding available for this kind of research and its contested status relative to other forms of educational research (Oancea and Bridges, 2009). A number of factors may compound those disadvantages: for example, a history of scepticism about philosophy, and about analytical philosophy in particular, as a subject in HE-based ITE programmes; a 'hermeneutic of suspicion' about philosophy in policy circles (Conroy, Davis and Enslin, 2009, p. 158); a sense of unease among many philosophers of education about what counts as reasonable expectations of practical relevance for their discipline. Together these challenges suggest, as McLaughlin (2000, p. 443) observed, that 'the modesty of philosophy must extend both to an acknowledgment that its contribution to educational policy is a partial one, and to its acceptance that its contribution must be offered in relation and dialogue with other reflective and critical resources and with the contingencies of circumstance and practice'.

Correspondence: Alis Oancea, University of Oxford Department of Education, 15 Norham Gardens, Oxford OX2 6PY, UK; Janet Orchard, University of Bristol School of Education, Helen Wodehouse Building, 35 Berkeley Square, Clifton BS8 1JA, UK. Emails: alis.oancea@education.ox.ac.uk; edjlo@bristol.ac.uk

\section{References}

Aldridge (2011) The role of HE in teacher education: a reorientation towards ontology PPfTE presentation at the Department of Education, University of Oxford

Aristotle (1975) Ethica Nicomachea, Vol. IX of The Works of Aristotle. Oxford: Oxford University Press.

Biesta, G. (2012) The future of teacher education: Competence, evidence or wisdom? PPfTE presentation to the Annual Conference of the PESGB, New College, Oxford Biesta, G. (2011) The future of teacher education: Competence, evidence or wisdom? PPfTE presentation, Department of Education, University of Oxford 
Bridges, D. (2003a) 'Fiction Written under Oath?' Essays in philosophy and educational research. Dordrecht: Kluwer.

Bridges, D. (2003b) Six stories in search of a character? 'The philosopher' in an educational research group. In: P. Smeyers \& M. DePaepe (eds)Beyond Empiricism: On criteria for educational research. Leuven: Leuven University Press.

Bridges, D. and Watts, M. (2009) Educational research and policy: Epistemological considerations. In: D. Bridges, P. Smeyers and R. Smith (Eds) Evidence-Based Education Policy. What evidence? What basis? What policy? Chichester: WileyBlackwell, pp. 36-57.

Bridges, D., Smeyers, P. and Smith, R. (Eds) Evidence-Based Education Policy. What evidence? What basis? What policy? Chichester: Wiley-Blackwell.

Britton, J. (1972) Language and Learning. London, Heinemann

Cavell, S. (1979) The Claim of Reason: Wittgenstein, Skepticism, Morality, and Tragedy. Oxford: Oxford UP.

Clifford, W. (1879) The ethics of belief. In: Lectures and Essays, vol. 2. London: Macmillan.

Conroy, J., Davis, R.A., and Enslin, P. (2009) Philosophy as a basis for policy and practice: What confidence can we have in philosophical analysis and argument? In: D. Bridges, P. Smeyers and R. Smith (Eds) Evidence-Based Education Policy. What evidence? What basis? What policy? Chichester: Wiley-Blackwell, pp. 157174.

Davis, A. (1999) Prescribing teaching methods. Journal of Philosophy of Education, 33(3), pp. 387-402.

DELNI/DENI (2010) Teacher Education in a Climate of Change. Consultation document.

Department for Education (2010) The Importance of Teaching - The Schools White Paper 2010. Available at: https://www.education.gov.uk/

Department for Education (2011a) Training our Next Generation of Outstanding Teachers. An improvement strategy for discussion. Available at: http://www.education.gov.uk/

Department for Education (2011b) Teachers' Standards in England from September 2012. Available at: http://dera.ioe.ac.uk/13187

Donaldson, G. (2011) Teaching Scotland's Future: Report of a review of teacher education. Edinburgh: Scottish Government.

Edwards, A., Gilroy, P. and Hartley, D. (2003) Rethinking Teacher Education Collaborative responses to uncertainty. London: Routledge/Falmer.

Ellis, V. (2012) 'Living with ghosts: 'Disciplines', envy and the future of teacher education', Changing English: Studies in Culture and Education 19,3: 155-166

Ellis, V. (2011) After the ghosts: 'Disciplines', envy and the future of teacher education

PPfTE presentation at the Department of Education, University of Oxford

Ellis, V., Edwards, A. and Smagorinsky, P. (2010) Cultural-Historical Perspectives on Teacher Education and Development. Abingdon, Routledge

Fielding, M. (2000) Education policy and the challenge of living philosophy. Journal of Education Policy, 15(4), pp. 377-381. 
Foreman-Peck, L. (2012) The education of teachers: Taking the long view. PPfTE presentation to the Annual Conference of the PESGB, New College, Oxford

Furlong, J., Hagger, H., Butcher, C. and Howson, J. (2006) Review of Initial Teacher Training Provision in Wales. National Assembly for Wales (The Furlong Report).

Furlong, J., Barton, L., Miles, S., Whiting, C., andWhitty, G. (2000) Teacher Education in Transition. Buckingham: OUP.

Gove, M. (2011) Letter to Sally Coates on the standards for teaching, 14 July.

Gronn, P. (2003) The New Work of Educational Leaders: Changing Leadership practice in an era of school reform. London, Paul Chapman Publishing.

Griffiths, M. (2012) Re-thinking the relevance of philosophy of education for educational policy making. Educational Philosophy and Theory, e-first.

Griffiths, M. (2011) Teaching teachers teaching: Why pedagogical relations matter for education policy and practice PPfTE presentation, Moray House, University of

Edinburgh

GTCS (2006) Scottish Teacher Education Standards: http://www.gtcs.org.uk/.

GTCW (2011) Raising the Bar in ITET and Early Career Development. http://www.gtcw.org.uk/.

Harrison, A. (2012) Academies told they can hire unqualified teachers. Available at

http://www.bbc.co.uk/news/education-19017544

Heilbronn, R. (2012) Teacher educators as ethical agents: playfulness and solidarity PPfTE presentation, IOE University of London

Higgins, C. (2011) The Good Life of Teaching: An Ethics of Professional Practice Oxford, Wiley-Blackwell

Hinchliffe, G. (2012) Some Reflections on Teacher Authority, PPfTE presentation, IOE University of London

Hirst, P. H. and Carr, W. (2005) Philosophy and Education-A Symposium, Journal of Philosophy of Education, 39.4, pp. 615-32.

HMSO (2012) House of Commons Education Committee report, Great Teachers: attracting, training and retaining the best Available at http://www.publications.parliament.uk/pa/cm201213/cmselect/cmeduc/524/524.pdf

Hogan, P. (2012) Towards an Educational Understanding of Human Understanding Itself: a Critique of Theory in Teacher Education PPFTE presentation, IOE University of London

Laugier, S. (2011) Matter and mind: Cavell's (concept of) importance. In: MLN, Volume 126, Number 5, December, pp. 994-1003.

Levitt, R., Celia, C., Diepeveen, S., Chonaill, S. N., Rabinovich, L., and Tiessen, J. (2010) Assessing the Impact of Arts and Humanities Research at the University of Cambridge. Cambridge: Rand.

McLaughlin, T.H. (2000) Philosophy and educational policy: Possibilities, tensions and tasks. Journal of Educational Policy, 15 (4), pp. 441-457. 
Menter, I. (2011) The democratic intellect in teacher education - where is it? PPfTE presentation at the Department of Education, University of Oxford

Menter, I., Hulme, M., Murray, J., Campbell, A., Hextall, I., Jones, M., Mahony, P.

Procter, R. and Wall, K. (2010) Teacher education research in theUK: The state of the art. Revue Suisse des sciences de l'education, 32 (1), 121-142.

Mutton, T. (2012) What do we want the next generation of teachers to be like? PPfTE

presentation at the Department of Education, University of Oxford

Nutley, S. M., Walter, I. and Davies, H.T.O. (2007) Using Evidence: How research can inform publicservices. Bristol: Policy Press.

Oancea, A and Orchard, J.L. (2012) Philosophical Perspectives on the future of Teacher

Education. PPfTE presentation to the Annual Conference of the PESGB, New College,

Oxford.

Oancea, A. (2011a) Teachers, teacher education and educational research in the 1990s: $a$ (hi)story of critiques and silences. PPfTE presentation, Moray House, University of Edinburgh.

Oancea, A. (2011b) Interpretations and Practices of Research Impact across the Range of Disciplines. Final report. Oxford: Oxford University.

Oancea, A. (2011c) Philosophy of education. In: J. Arthur (Ed) The Routledge Companion to Education. London: Routledge.

Oancea, A. and Bridges, D. (2009) Philosophy of education - its contribution and status since 1988. Oxford Review of Education, 35 (5), 553-568.

Oancea A. and Pring, R. (2008) The importance of being thorough: On systematic accumulations of 'what works' in education research. Journal of Philosophy of Education, 42(s1), pp. 4-15.

O’Neill, O. (2002) A Question of Trust. BBC Reith Lectures, 2002.

Orchard, J.L. (2011) Philosophical Perspectives on the future of Teacher Education,

PPfTE presentation, UCET Annual Conference.

Peters, R.S. (1966) The Ethics of Education. London: George Allen and Unwin Ltd.

Peters, R.S. (1973)(Ed) The Philosophy of Education. Oxford: Oxford University Press.

Pring, R. (2011) Bring Back Teaching PPfTE presentation, Moray House, University of

Edinburgh Available at http://www.teachingscotland.org.uk/education-in-

scotland/scotlands-education-system/45-bring-back-teaching.aspx

Saunders, L. (2012) Is There Such a Thing as 'Professional Knowledge' in Teaching?

PPfTE presentation, IOE University of London

Saunders, L. (Ed) (2007) Educational Research and Policy Making: Exploring the border country between research and policy. Abingdon and New York: Routledge.

Scottish Government (2011) Continuing to Build Excellence in Teaching: the Scottish Government's response to Teaching Scotland's Future. Available at:

http://www.scotland.gov.uk/Topics/Education/Schools/Teaching/SGresponse09032011

Standish, P. (2012) Exposed in Time PPfTE presentation, IOE University of London 
Winch, C. (2012) What can philosophy of education do for teacher education? PPfTE presentation to the Annual Conference of the PESGB, New College, Oxford Winch, C. (2011) What can philosophy of education do for teacher education? PPfTE presentation at the Department of Education, University of Oxford

Winch, C. and Gingell, J. (2004) Philosophy and Educational Policy.A critical introduction. London and New York: RoutledgeFalmer.

Wittgenstein, L. (2001) Philosophical Investigations. Oxford: Blackwell.

White, J.P. (2007) What Schools Are For and Why.PESGB Impact Pamphlet, 14. London: PESGB.

Whitty, G., Donoghue, M., Christie, D., Kirk, G., Menter, I., McNamara, O.,Moss, G., Oancea, A., Rogers, C. and Thompson, P. (2012) Prospects for the Future of Educational Research. London: BERA and UCET.

Williams, R. (1961) The Long Revolution. London: Chatto and Windus Wringe (2011) Learning to teach and becoming a teacher: Techne and phronesis PPfTE presentation to the Annual Conference of the PESGB, New College, Oxford

\section{NOTE}

\footnotetext{
${ }^{\mathrm{i}}$ The Philosophy of Education Society of Great Britain (PESGB) has sponsored a series of research symposia and conference workshops during 2011-13 called 'Philosophical Perspectives on the Future of Teacher Education'. The initiative has promoted dialogue between philosophers of education, teacher educators and other educationalists and stimulated philosophical reflection on teaching and teacher education by thinkers across a diverse range of intellectual traditions in philosophy of education; on themes highly relevant to concerns about quality and accountability in teaching and teacher education, with which policy makers have been preoccupied over several decades (see Oancea 2011a, Furlong et al. , 2000).
} 